\title{
Effects of combined inhibition of STAT3 and VEGFR2 pathways on the radiosensitivity of non-small-cell lung cancer cells
}

This article was published in the following Dove Medical Press journal:

OncoTargets and Therapy

\author{
Chenxi Hu$u^{1, *}$ \\ Wei Zhuang ${ }^{2, *}$ \\ Yun Qiao,** \\ Bin Liu ${ }^{2}$ \\ Liang Liu ${ }^{2}$ \\ Kaiyuan Hui' \\ Xiaodong Jiang ${ }^{1,2}$ \\ 'Tumor Laboratory, Department of \\ Oncology, The Affiliated Lianyungang \\ Hospital of Xuzhou Medical \\ University, Lianyungang City 222002 , \\ China; ${ }^{2}$ Department of Oncology, \\ The Affiliated Lianyungang Hospital \\ of Xuzhou Medical University, \\ Lianyungang City 222002, China \\ *These authors contributed equally \\ to this work
}

Purpose: The goals of this study were to determine the effects of combined inhibition of STAT3 and vascular endothelial growth factor receptor 2 (VEGFR2) pathways on the radiosensitivity of non-small-cell lung cancer (NSCLC) cells, and to assess the underlying mechanisms.

Methods: The expressions of VEGFR2, STAT3, related signaling molecules, hypoxia-inducible factor 1-alpha (HIF-1 $\alpha$ ), and cyclin D1 were determined by Western blotting. Radiosensitivity was assessed using the colony-forming assay, and cell cycle and cell death were analyzed by flow cytometry. A nude mouse xenograft tumor model of Calu-1 cells was established. The hepatorenal toxicity of the above-mentioned treatment on tumor-bearing mice was observed by H\&E staining. The expression of STAT3, VEGFR2, HIF-1 $\alpha$, and cyclin D1 of the transplanted tumor tissues was detected by immunohistochemistry. Apoptosis of tumor tissues was evaluated by TUNEL staining.

Results: In vitro, we selected two cell lines with high expression levels of STAT3, including Calu-1 cells that exhibit high VEGFR2 expression and A549 cells that exhibit low VEGFR2 expression. When apatinib treatment was combined with S3I-201, the expression of VEGFR2, STAT3, and their downstream signaling molecules was significantly decreased $(P<0.01)$. There was an increase in cell death and G2/M phase arrest after treatments, with the most significant changes occurring upon dual inhibition of STAT3 and VEGFR2 $(P<0.01)$. In vivo, combined treatment of radiotherapy and dual inhibition of VEGFR2 and STAT3 was well tolerated and did not deliver additional toxicity. Compared with the control group and the radiation treatment (RT) + apatinib or RT + S3I-201 duplex group, the expression level of STAT3, p-STAT3, VEGFR2, HIF-1 $\alpha$, and cyclin D1 in the triple group (RT + apatinib + S3I-201) was the lowest, and the proportion of apoptotic cells was the highest $(P<0.05)$.

Conclusion: The combined inhibition of VEGFR2 and STAT3 is effective in enhancing radiosensitizing effects in NSCLC cells.

Keywords: STAT3, VEGFR2, non-small-cell lung cancer, radiosensitivity

\section{Introduction}

Lung cancer is the leading cause of cancer-related morbidity and mortality, and non-small-cell lung cancer (NSCLC) accounts for $80 \%$ of total lung cancer cases. Radiotherapy is one of the main treatments for patients with late-stage NSCLC; ${ }^{1}$ however, it sometimes does not generate satisfactory results due to the resistance of some cancer cells to radiation. Although sensitizing cancer cells to radiotherapy has become a key subject of clinical research, effective radiosensitizing agents still remain to be identified. In addition to the clinical benefits directly related to the anti-angiogenic 
property of anti-angiogenic drugs, these agents may also have radiosensitizing effects. The mechanisms underlying these effects may not only involve inhibition of vascular endothelial growth factor receptor 2 (VEGFR2) from the endothelial cells of blood vessels in cancer tissues, but also on whether cancer cells express VEGR2. Our group conducted a series of studies to determine the efficacy of radiotherapy in combination with endostatin, an anti-angiogenic drug with several targets including VEGFR2, in treating NSCLC. ${ }^{2-9}$ Our results demonstrated that the combined treatment had a synergistic effect in increasing the radiosensitivity of high VEGFR2-expressing NSCLC cells. However, VEGFR2 inhibition improves clinical symptoms and extends remission, but did not significantly extend the overall survival (OS) of patients. Similarly, many other investigators have also reported that inhibition of VEGFR2 improves clinical symptoms and increases the period of alleviation, but fails to significantly extend survival. ${ }^{10}$

The radiosensitivity of tumor cells is associated with a variety of molecular regulations in tumor microenvironment. VEGFR2 is a tyrosine kinase receptor which is activated, through a variety of pathways, to the downstream signal molecules; STAT3 is one of the intersections of these pathways. An in vitro study by Gurbuz et $\mathrm{al}^{11}$ showed a positive correlation between STAT3 and VEGFR2 protein levels in prostate cancer cells. A study by Lin et $\mathrm{al}^{12}$ showed that the high expression of STAT3 is associated with poor prognosis, and that it is an independent factor for poor prognosis in patients with gliomas. Another in vivo study by Spitzner et al $^{13}$ showed that STAT3 inhibitors can increase the sensitivity of colorectal cancer cells to radiotherapy and chemotherapy, but the mechanism is not yet clear. So, a possible explanation for this phenomenon is that when VEGFR2 is inhibited, tumor cells may resist radiotherapy via the STAT3 pathway.

Recent studies have shown that STAT3 can function as an oncogene, as it promotes tumor cell growth and blocks apoptosis in a number of cancer cells. ${ }^{14-16}$ In addition, STAT3 regulates genes involved in tumor cell proliferation, invasion, and metastasis. An in vitro study by Nechemia-Arbely et $\mathrm{al}^{17}$ showed that STAT3 activation in kidney tumor cells cultured under hypoxic or normoxic conditions led to the upregulation of hypoxia-inducible factor $1 \alpha$ (HIF- $1 \alpha$ ), resulting in radiotherapy resistance. Another study by Zhang et $\mathrm{al}^{18}$ showed a positive correlation between cyclin D1 and STAT3 protein levels in gastric cancer. Specifically, activation of STAT3 upregulated expression of its target gene cyclin D1, which correlated with the sensitivity of cells to radiotherapy. ${ }^{19}$
Together, these studies suggest that when VEGFR2 is inhibited, inflammatory mediators and growth factors in the tumor microenvironment can also activate STAT3. STAT3 can also directly or indirectly regulate cyclin D1 expression, leading to effects on cancer cell death, cell cycle progression, and sensitivity to radiotherapy. In this study, we used in vitro and in vivo experimental models to determine the role of STAT3-mediated, VEGFR2-independent pathway in affecting the radiosensitivity of NSCLC as well as the underlying mechanisms.

\section{Materials and methods Materials and reagents}

The following cell lines were purchased from the Shanghai Institutes for Biological Sciences, Chinese Academy of Sciences: Calu-1 (human squamous cell carcinoma), NCI-H358 (human lung adenocarcinoma), NCI-H460 (human lung large-cell carcinoma), NCI-H1975 (human lung adenocarcinoma), NCI-H1650 (human lung adenocarcinoma), 95D (human giant cell lung carcinoma cell lines with high metastatic potential), NCI-H292 (human lung mucoepidermoid carcinoma-lymph node metastatic strain), A549 (human lung adenocarcinoma), and NCI-H1299 (human lung adenocarcinoma-lymph node metastatic strain). McCoy's 5A and RPMI-1640 media were from Sigma Aldrich Co. (St Louis, MO, USA), FBS was from Si Ji Qing (Hangzhou, China). Apatinib (selective VEGFR2 inhibitor) and S3I-201 (inhibitor of STAT3) were purchased from Selleckchem.com (Houston, TX, USA). VEGFR2, HIF-1 $\alpha$, Akt, ERK1/2, p-38, p-VEGFR2, p-Akt, p-ERK1/2, p-p38, STAT3, and p-STAT3 antibodies were obtained from Cell Signaling Technology (Danvers, MA, USA). Apoptosis and cell cycle kits were from Nanjing Keygentec (Nanjing, China).

\section{Cell culture and radiation}

Calu- 1 cells in McCoy's 5A medium containing 10\% FBS were cultured in an incubator at $37^{\circ} \mathrm{C}$ and $5 \% \mathrm{CO}_{2}$. NCI-H358, NCI-H460, NCI-H292, NCI-H1650, A549, NCI-H1975, and NCI-H1299 cells in RPMI-1640 medium containing $10 \% \mathrm{FBS}$ were cultured in an incubator at $37^{\circ} \mathrm{C}$ and $5 \%$ $\mathrm{CO}_{2}$. Radiation was applied at $6 \mathrm{MV} \mathrm{X}$-ray energy and a dose rate of $200 \mathrm{cGy} / \mathrm{min}$ with a source-skin distance of $100 \mathrm{~cm}$.

\section{Western blot analysis}

Total cell protein was extracted using RIPA buffer and denatured by boiling. Samples were electrophoresed on different concentrations of SDS-PAGE gels depending on 
each sample's molecular weight, and electrophoretically transferred to PVDF membranes. After blocking in 5\% BSA for 1 hour, the membranes were incubated with the respective antibodies $(1: 1,000)$ at $4^{\circ} \mathrm{C}$ overnight. The membranes were rinsed three times with PBS solution with Tween detergent (PBST), and then incubated with the corresponding ALPconjugated secondary antibodies $(1: 1,000)$ for 1 hour. After being rinsed, the chemiluminescent detection system and film were used for protein detection. Each experiment was repeated three times.

\section{Apoptosis assay by flow cytometry}

Cells were exposed to 2 Gy radiation after pretreatment with S3I-201 for 48 hours and with apatinib for 24 hours, followed by an additional incubation for 24 hours. Then EDTA-free trypsin solution was added to make a cell suspension. Cells were washed twice with cold PBS and centrifuged at $1,500 \mathrm{rpm}$ for 5 minutes. After the cells were finally resuspended in $500 \mu \mathrm{L}$ of binding buffer, $5 \mu \mathrm{L}$ of fluorescein isothiocyanate-labeled Annexin V and propidium iodide (PI) were added, mixed well, and the cells were incubated in the dark for 15 minutes. Cells were analyzed on a flow cytometer. Each experiment was repeated three times.

\section{Cell cycle analysis}

After cells were treated as mentioned previously, cells were collected and fixed in $70 \%$ cold ethanol at $4^{\circ} \mathrm{C}$ for 24 hours. Fixed cells were washed with PBS and $100 \mu \mathrm{L}$ of RNase A was added. After incubation in a water bath at $37^{\circ} \mathrm{C}$ for 30 minutes, $400 \mu \mathrm{L}$ of PI solution was added, mixed well, and the cells were incubated in the dark at $4^{\circ} \mathrm{C}$ for 30 minutes. Then cells were analyzed on a flow cytometer. Each experiment was repeated three times.

\section{Colony-forming experiments}

Different strains of cells in their log growth phase were used. Cells were seeded at a density $10^{2}-10^{5}$ cells/well in six-well plates. Cells were divided into different treatment groups in triplicates: control, apatinib, S3I-201, radiation treatment (RT), RT + apatinib, RT + S3I-201, and RT + apatinib + S3I-201. After the attachment of cells, cells in each group were treated accordingly with apatinib treatment lasting for 24 hours and S3I-201 treatment lasting for 48 hours. After cells were exposed to different radiation doses $(2,4,6$, and $8 \mathrm{~Gy})$ at room temperature, they were cultured for 10-14 days, after which they were fixed and fast Giemsa staining was performed. Culture plates were placed upside down, and attached to a transparent film with grids on the bottom for colony numeration by the naked eye. The colonies with a diameter of $\geq 0.2 \mathrm{~mm}$ were counted and recorded. Survival fraction $(\mathrm{SF})=$ number of colonies/ (number of seeded cells $\times$ plating efficiency $[\mathrm{PE}]) \times 100 \%$. Each experiment was repeated three times.

\section{Xenograft mouse model}

Four-week-old BALB/c nude mice were obtained from Vital River Laboratory Animal Technology Co., Ltd (Beijing, China). All animal experiments were performed according to protocols approved by the Research Ethics Committee of the Affiliated Lianyungang Hospital of Xuzhou Medical University. About $5 \times 10^{6}$ cells suspended in $100 \mu \mathrm{L}$ of PBS were subcutaneously injected into the mice. A total of 25 nude mice were randomly assigned to five groups $(n=5)$ : control, RT, RT + apatinib, RT + S3I-201, and RT + apatinib + S3I201. Apatinib (200 mg/kg, once a day), S3I-201 (5 mg/kg, every 3 days), and radiotherapy were administered for 14 days. The weight of the mice and the diameter of the tumor were recorded on the next day. Tumor formation was evaluated every 2 days for 14 days after start of treatment. Four groups of animals were exposed to 10 Gy radiation (radiation was applied at $6 \mathrm{MV}$ X-ray and a dose rate of $2 \mathrm{~Gy} / \mathrm{min}$ with a source-skin distance of $100 \mathrm{~cm}, 2$ Gy per day, for 5 days). The mice were sacrificed on the next day after the last administration and the tumor was weighed to observe the antitumor effect. The tumor volumes were calculated using the equation volume $\left(\mathrm{mm}^{3}\right)=$ length $\times$ width $^{2} / 2$.

\section{Immunohistochemistry (IHC)}

The primary antibodies were prepared at a 1:200 dilution. The secondary antibody (PV kit) was purchased from Zhongshan Golden Bridge. To standardize the assessment procedure, the immunohistochemically stained tissues were evaluated by two experienced pathologists. Staining intensities were estimated in five random fields per section by three independent observers individually.

\section{TUNEL staining}

Tissues were embedded, sectioned, and deparaffinized. The specimens were incubated with proteinase $\mathrm{K}(40 \mu \mathrm{g} / \mathrm{mL})$ for 1 hour at $37^{\circ} \mathrm{C}$, and then treated with $2 \% \mathrm{H}_{2} \mathrm{O}_{2}$ in distilled water for 30 minutes at $37^{\circ} \mathrm{C}$. After enzymatic reaction, sections were washed with PBS, and incubated with streptavidin-HRP conjugate for 30 minutes at $37^{\circ} \mathrm{C}$ in a humified chamber. The sections were stained with diaminobenzine and counterstained with hematoxylin, and observed under a light microscope. 


\section{Statistical analysis}

SPSS 16.0 software was used to conduct statistical analysis. Data are presented as mean \pm SD. Multiple comparison was conducted using one-way ANOVA, between-group comparisons were conducted using two-sample $t$-test, and correlation analysis was conducted using Pearson's correlation coefficient. Statistical significance was set at $P<0.05$.

\section{Results}

\section{Expression of STAT3 and p-STAT3 in} different strains of NSCLC cells

The expression of STAT3 and p-STAT3 in NSCLC cell lines was analyzed by Western blotting and was found to be significantly different ( $P<0.01$; Figure $1 \mathrm{~A}-\mathrm{D})$. Calu- 1 cells, which showed high expression of VEGFR2 and p-STAT3,

A

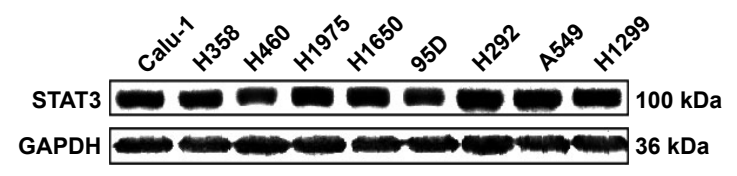

C
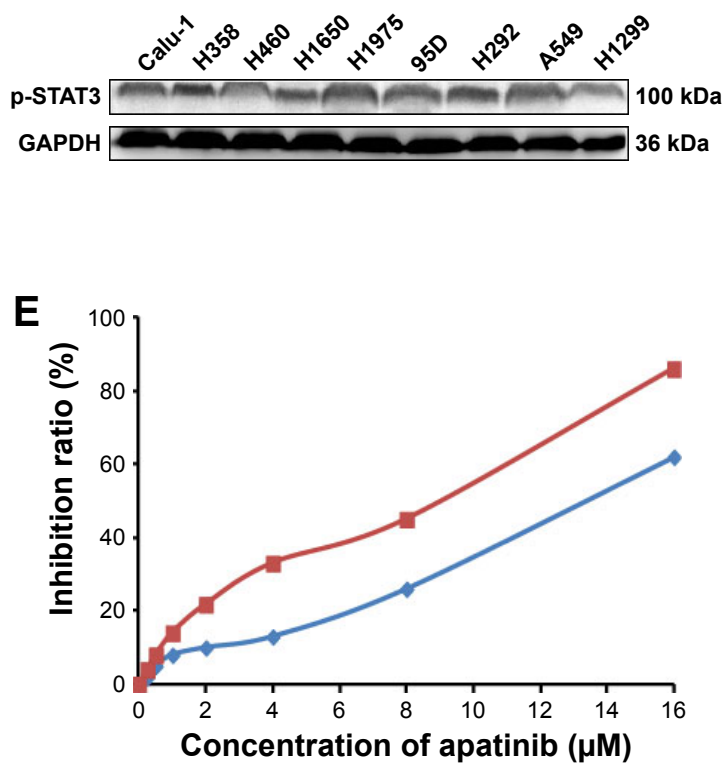

and A549 cells, which had low VEGFR2 expression ${ }^{20}$ and high p-STAT3 expression, were selected for subsequent experiments. The proliferation of Calu- 1 and A549 cells was significantly inhibited upon apatinib and S3I-201 treatment at different concentrations, with an $\mathrm{IC}_{20}$ of $1.78 \mu \mathrm{M} / 6.40 \mu \mathrm{M}$ and $100 \mu \mathrm{M} / 192 \mu \mathrm{M}$, respectively (Figure $1 \mathrm{E}$ and $\mathrm{F}$ ). These concentrations were used in subsequent experiments.

\section{Effects of dual inhibition of VEGFR2 and} STAT3 on their downstream target genes and protein expression in Calu-I cells

Compared to control cells, dual inhibition of VEGFR2 and STAT3 by adding apatinib and S3I-201 did not significantly affect their protein levels or those of their downstream signaling molecules AKT and ERK1/2 $(P>0.05)$
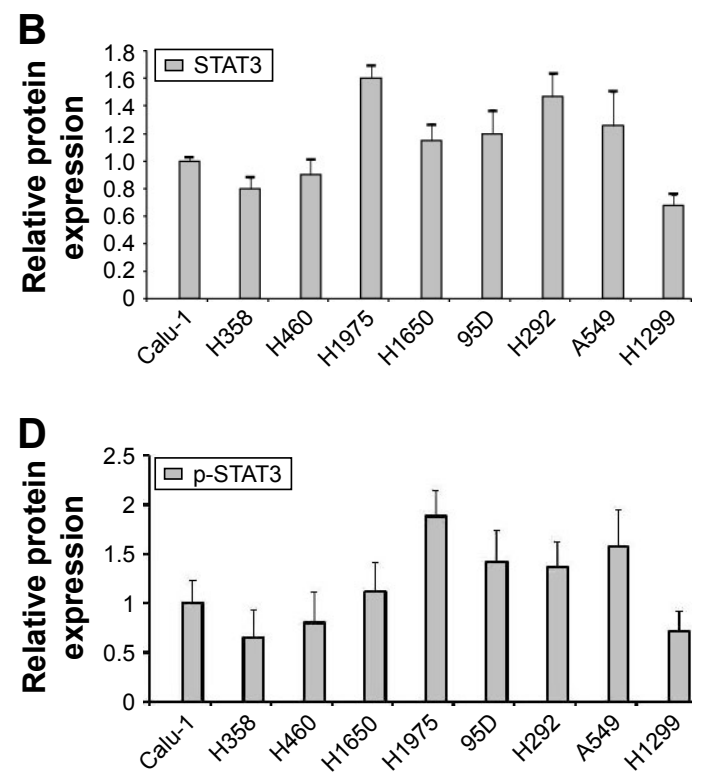

$\mathbf{F}$

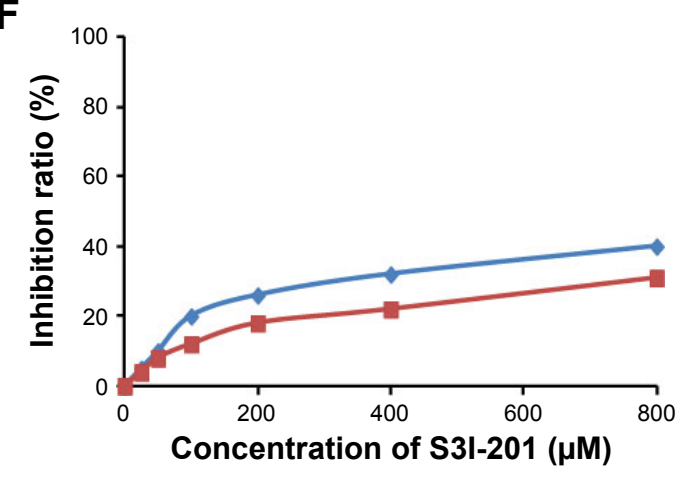

Figure I Expression of STAT3 and p-STAT3 in different strains of NSCLC cells.

Notes: (A, C) Western blotting was used to determine STAT3 and p-STAT3 protein expression in nine NSCLC cell lines (Calu-I, H358, H460, HI975, HI650, 95D, H292, A549, and HI299). (B, D) Histograms of STAT3 and p-STAT3 protein levels. (E, F) The death rate of Calu-I and A549 cells by apatinib and S3I-20I ( $\mathrm{n}=3$ ).

Abbreviation: NSCLC, non-small-cell lung cancer. 
A1

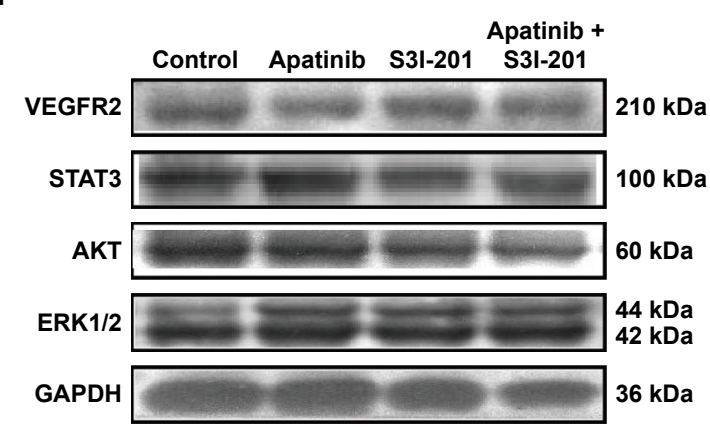

B1

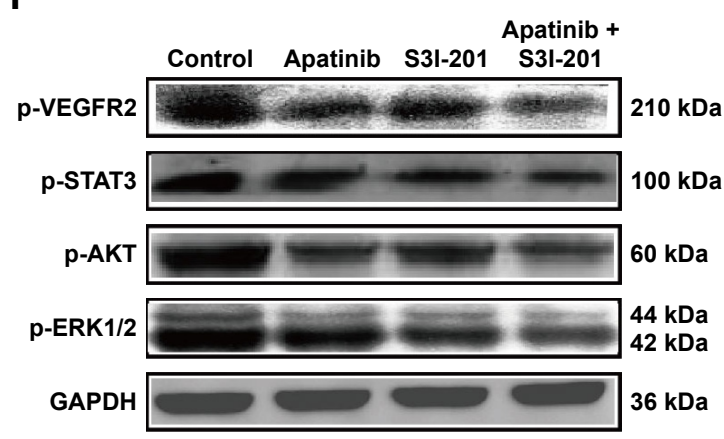

C1

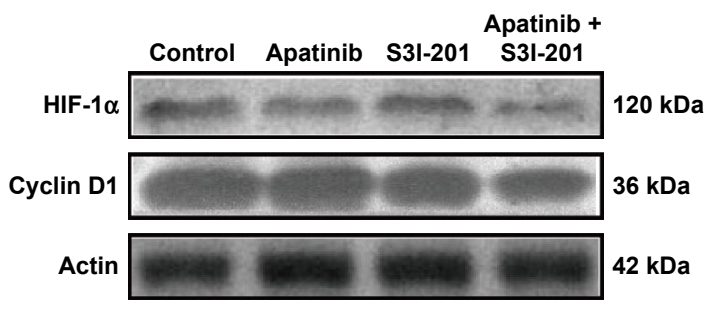

A2

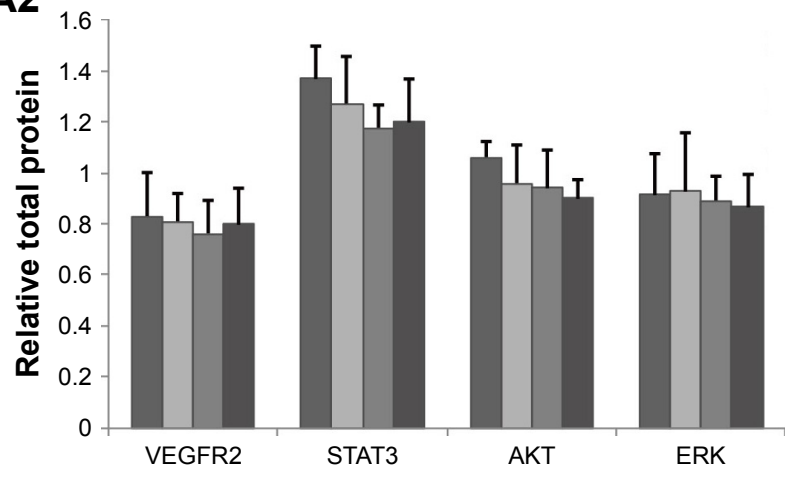

B2

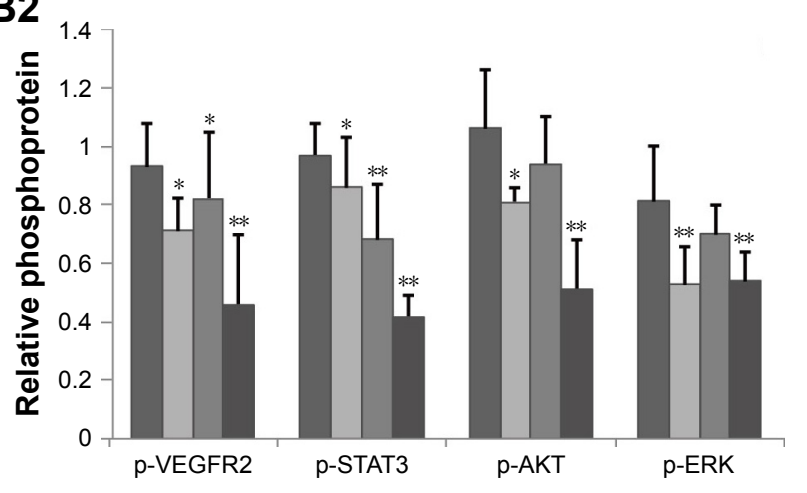

C2

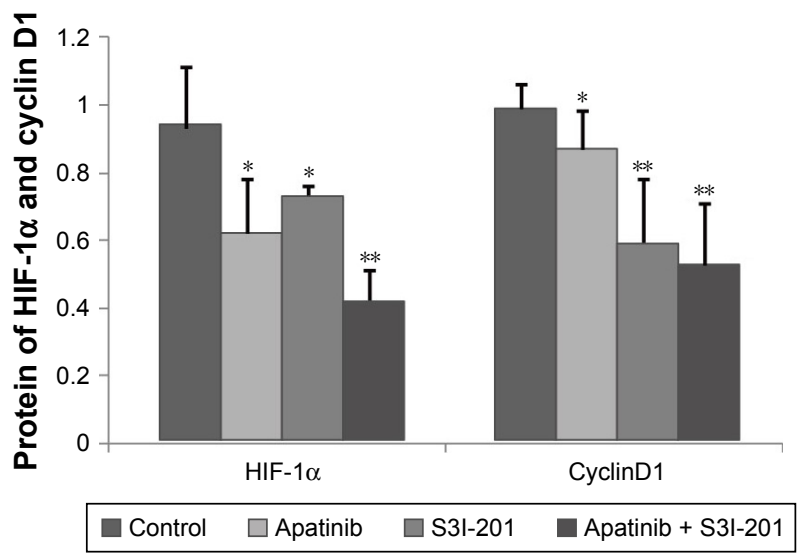

Figure 2 Effects of dual inhibition of VEGFR2 and STAT3 on their downstream target genes and protein expression in Calu-I cells.

Notes: (AI, A2) As determined by Western blotting, inhibition of VEGFR2/STAT3 alone or dual inhibition of VEGFR2 and STAT3 had no significant effects on the total protein levels of VEGFR2 and STAT3 as well as their downstream signaling molecules AKT and ERKI/2. (BI, B2, CI, C2) Western blotting was used to measure the expression of P-VEGFR2, P-STAT3, p-AKT, p-ERK, HIF-I $\alpha$, and cyclin DI. Inhibition of VEGFR2 alone inhibited phosphorylation of proteins. Dual inhibition of VEGFR2 and STAT3 inhibited protein phosphorylation as well as HIF-I $\alpha$ and cyclin $D I$ expression $(P<0.0 I ; P<0.0 I ; P<0.01 ; P<0.0 I ; P<0.01 ; P<0.0 I$, respectively). $* P<0.05 ; * * P<0.0 I ; n=3$. Abbreviation: VEGFR2, vascular endothelial growth factor receptor 2.

(Figure 2A1 and A2). However, compared to the control, apatinib treatment significantly inhibited the protein expression of p-VEGFR2, p-STAT3, p-AKT, and p-ERK1/2 $(P<0.05 ; P<0.05 ; P<0.05 ; P<0.01$, respectively), and S3I201 treatment significantly inhibited the protein expression of p-VEGFR2 and p-STAT3 $(P<0.05 ; P<0.01)$. HIF- $1 \alpha$ and cyclin $\mathrm{D} 1$ protein expression was also significantly reduced after apatinib and S3I-201 treatment $(P<0.05 ; P<0.05$; $P<0.05 ; P<0.01)$. After cells were treated with both apatinib and S3I-201 to simultaneously inhibit VEGFR2 and STAT3, the protein expression of p-VEGFR2 and p-STAT3 as well as their downstream signaling molecules p-AKT, p-ERK1/2, HIF-1 $\alpha$, and cyclin D1 showed an even greater reduction than that for the control $(P<0.01$; 
$P<0.01 ; P<0.01 ; P<0.01 ; P<0.01 ; P<0.01$, respectively) (Figure 2B1, B2, C1, C2).

\section{Cell death, cell cycle, and radiosensitivity in Calu- I and A549 cells after combined treatment of radiotherapy together with dual inhibition of VEGFR2 and STAT3}

Combination of dual inhibition of VEGFR2 and STAT3 with radiotherapy caused significantly more cell death in Calu-1 cells than in A549 cells. Cell death induced by treatment with apatinib plus radiotherapy was significantly more pronounced than treatment with radiotherapy alone in Calu-1 cells; however, this treatment-related difference in cell death was not found in A549 cells, which makes the difference between Calu-1 and A549 cells in this regard highly significant $(P<0.01)$. Interestingly enough, cell death induced by treatment of radiotherapy together with dual inhibition of VEGFR2 and STAT3was significantly more pronounced than treatment with radiotherapy alone in A549 cells (Figure 3A). Combination of dual inhibition of VEGFR2 and STAT3 with radiotherapy had significant effects on the cell cycle in Calu-1 cells compared to that in A549 cells. Inhibition of VEGFR2 alone had a very limited effect on the cell cycle in A549 cells, but when both VEGFR2 and STAT3 were inhibited, the number of cells in $\mathrm{G} 2 / \mathrm{M}$ phase arrest was significantly increased $(P<0.01)$ (Figure 3B and C). The radiotherapy-sensitizing effects of inhibitor VEGFR2 alone were more significant in Calu-1 cells (sensitization enhancement ratio $[\mathrm{SER}]=1.39$ ) than in A549 cells $(\mathrm{SER}=1.06)(P<0.01)$. In contrast, the radiotherapy-sensitizing effects of inhibiting both VEGFR2 and STAT3 increased in both A549 (SER =1.36) and Calu-1 cells (SER $=1.72)(P<0.01 ; P<0.01)$ (Figure 3D).

\section{Toxicity analysis for treatments with apatinib and S3I-20I in mice bearing Calu-I cells}

About $5 \times 10^{6}$ Calu-1 cells were subcutaneously injected into the mice. Ten days later, apatinib $(200 \mathrm{mg} / \mathrm{kg}$, once a day), S3I-201 (5 mg/kg, every 3 days), and radiotherapy were administered for 14 days. Four groups of animals were exposed to 10 Gy radiation (radiation was applied at $6 \mathrm{MV}$ X-ray and a dose rate of $2 \mathrm{~Gy} / \mathrm{min}$ with a source-skin distance of $100 \mathrm{~cm}, 2 \mathrm{~Gy} \mathrm{X} /$ day, for five times). These mice were sacrificed on the next day after the last administration, and the tumor weight was weighed to observe the antitumor effect (Figure 4A). These mice were used in subsequent experiments. In the toxicity analysis, we found that ionizing radiation combined with apatinib and S3I-201 did not lead to significant weight loss or treatment-related deaths (Figure 4B). Histopathology of harvested normal vital organ tissues (lung, liver, kidney, and spleen) revealed no evidence of hematological toxicity after treatment with single or combined RT, apatinib, and S3I-201 (Figure 4C). We conclude that the combined treatment of radiotherapy and dual inhibition of VEGFR2 and STAT3 was well tolerated and did not deliver additional toxicity.

\section{Effects of combined treatment of radiotherapy together with dual inhibition of VEGFR2 and STAT3 on the expression of downstream signaling molecules in tumor tissues}

Tumor tissues from xenograft mice model bearing Calu-1 were analyzed by IHC, and the effects of combined treatment of radiotherapy together with dual inhibition of VEGFR 2 and STAT3 on the protein levels of VEGFR2, STAT3, p-STAT3, HIF-1 $\alpha$, and cyclin D1 were also analyzed. Compared to the control, RT + apatinib treatment significantly inhibited the protein expression of VEGFR2, HIF-1 $\alpha$, and cyclin D1 $(P<0.05 ; P<0.05 ; P<0.05)$, and RT $+\mathrm{S} 3 \mathrm{I}-201$ treatment significantly inhibited the protein expression of p-STAT3, HIF-1 $\alpha$, and cyclin D1 $(P<0.05 ; P<0.05 ; P<0.05)$. After mice were treated with RT + apatinib + S3I-201, the protein expression of VEGFR2 and p-STAT3 as well as their downstream signaling molecules HIF-1 $\alpha$ and cyclin D1 showed an even greater reduction than that of the control $(P<0.05$; $P<0.05 ; P<0.01 ; P<0.01$ ) (Figure 5).

\section{Combined treatment of radiotherapy together with dual inhibition of VEGFR2 and STAT3 in mice bearing Calu-I cells}

Apoptosis of tumor tissues was evaluated by TUNEL staining. Apoptosis induced by treatment with apatinib or S3I-201 plus radiotherapy was significantly more pronounced than treatment with radiotherapy alone $(P<0.05 ; P<0.05)$. Radiotherapy together with dual inhibition of VEGFR2 and STAT3 induced most apoptosis in tumor tissues $(P<0.01)$ (Figure 6A). Compared to treatment with radiotherapy alone, growth of tumors in treatment with apatinib or S3I-201 plus radiotherapy mice was significantly inhibited $(P<0.05 ; P<0.05)$. Radiotherapy together with dual inhibition of VEGFR2 and STAT3 exhibited a significant retardation of tumor growth when compared with radiotherapy together with single apatinib or S3I-201 $(P<0.01)$ (Figure 6B and C). From these 
A

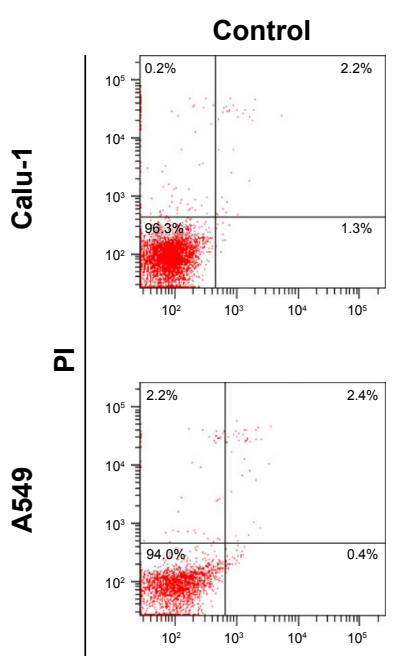

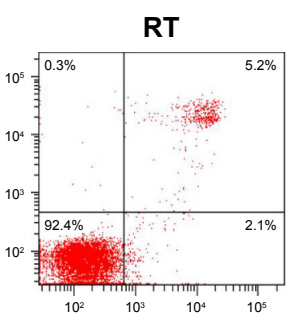
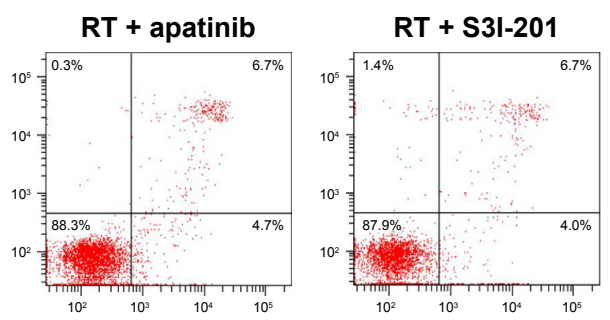

RT + apatinib + S3I-201
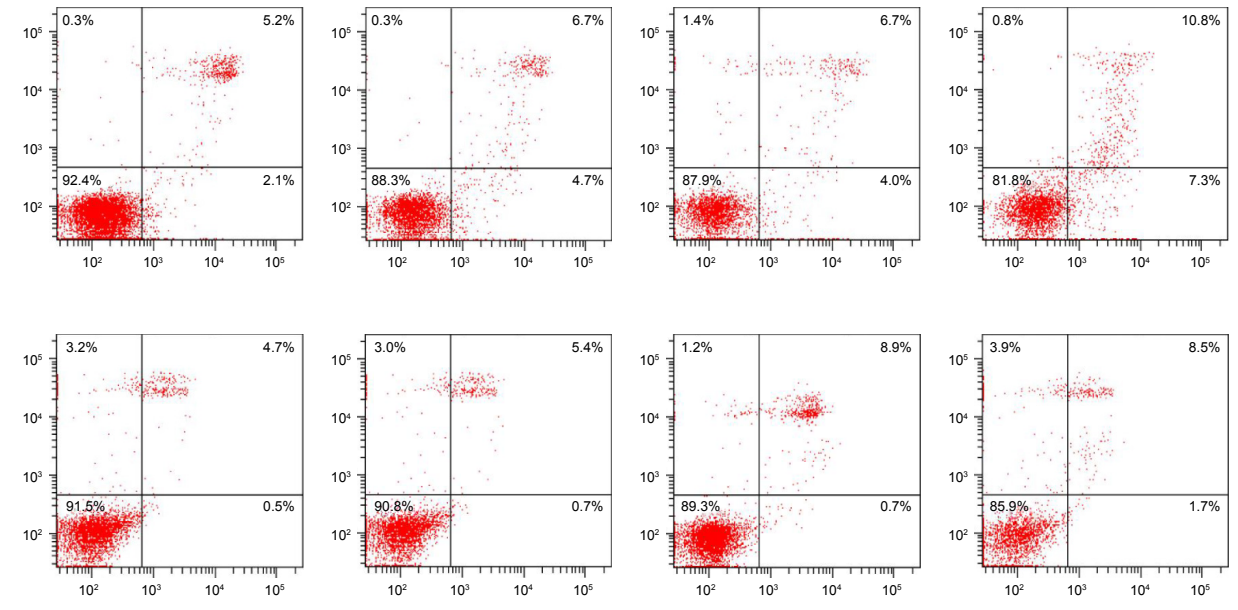

\section{Annexin-V FITC}
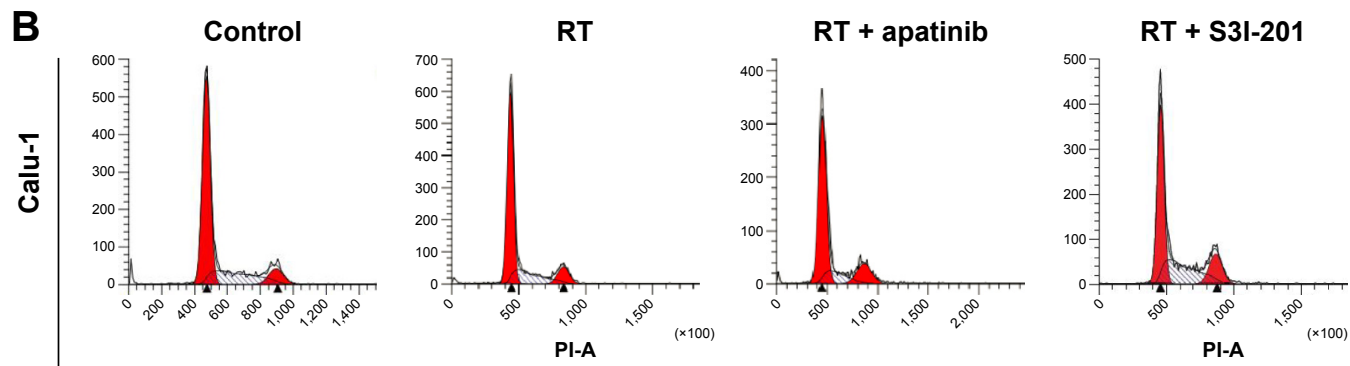

RT + apatinib + S3I-201
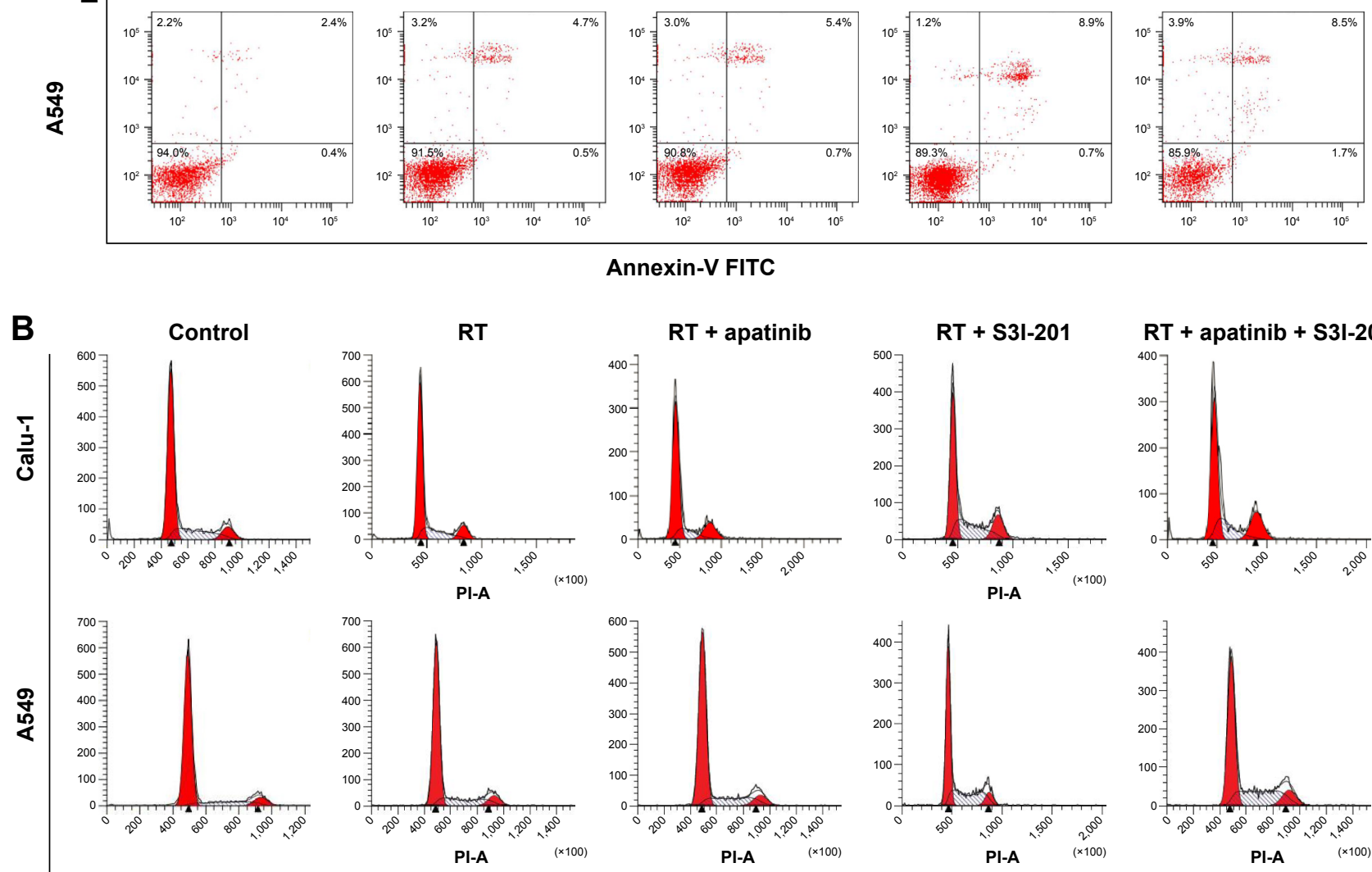

\section{Cell cycle of cell}
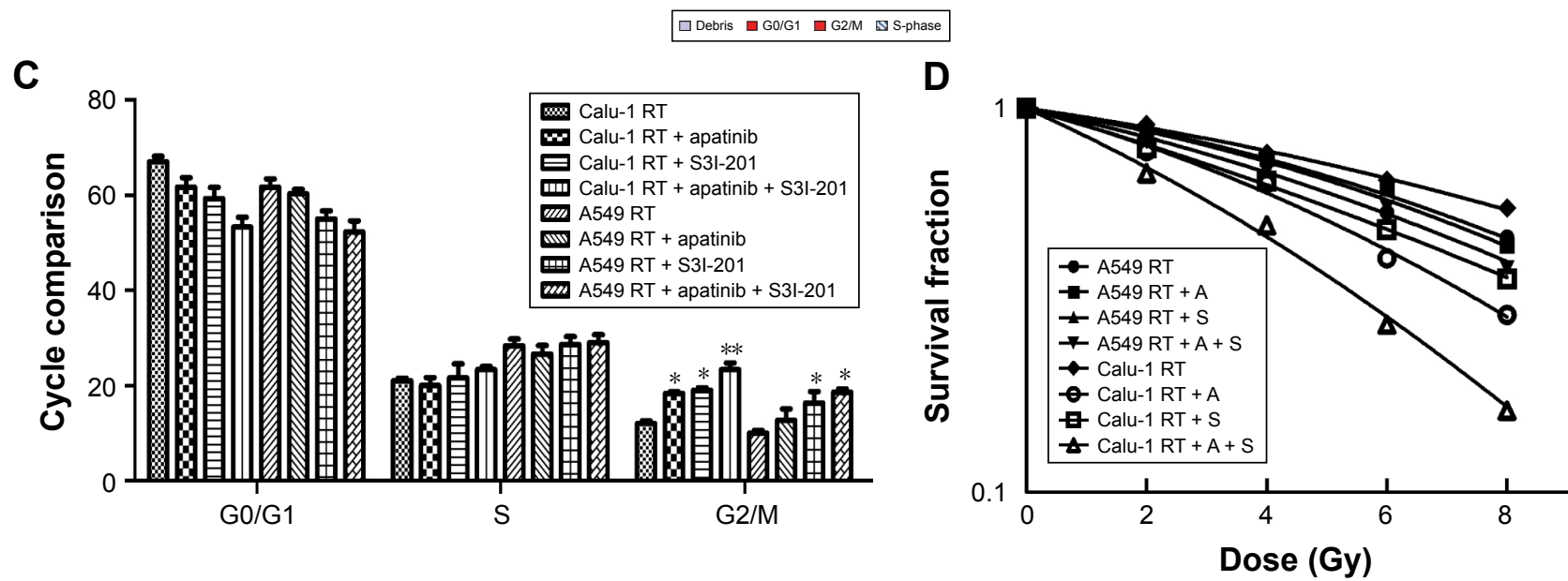

Figure 3 Cell death, cell cycle, and radiosensitivity in Calu-I and A549 cells after combined treatment of radiotherapy together with dual inhibition of VEGFR2 and STAT3. Notes: (A) Combination of dual inhibition of VEGFR2 and STAT3 with radiotherapy caused significantly more cell death in Calu-I cells than in A549 cells $(P<0.01)$. (B, C) Combination of dual inhibition of VEGFR2 and STAT3 with radiotherapy had significant effects on the cell cycle in Calu-I cells compared to A549 cells ( $P<0.01)$. (D) Combination of dual inhibition of VEGFR2 and STAT3 with radiotherapy resulted in a larger increase in radiosensitivity in Calu-I cells than in A549 cells. $* P<0.05$; $* * P<0.01 ; n=3$.

Abbreviations: PI, propidium iodide; FITC, fluorescein isothiocyanate; RT, radiation treatment; A, apatinib; S, S3I-20I. 
A

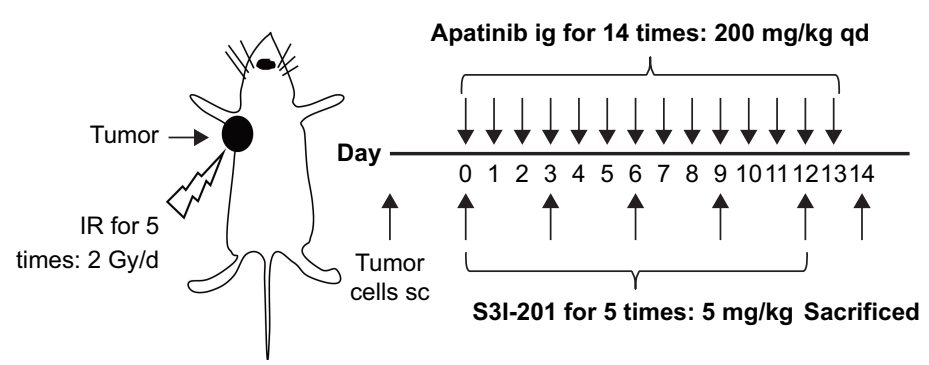

B

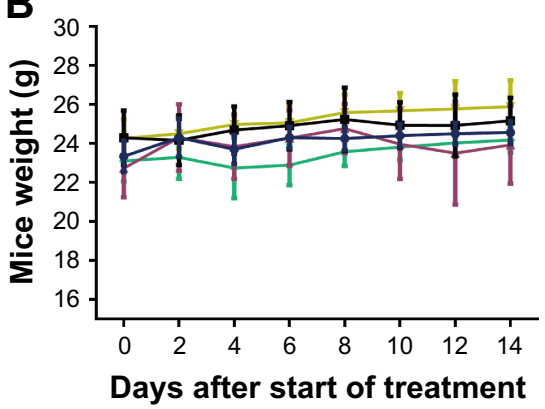

C
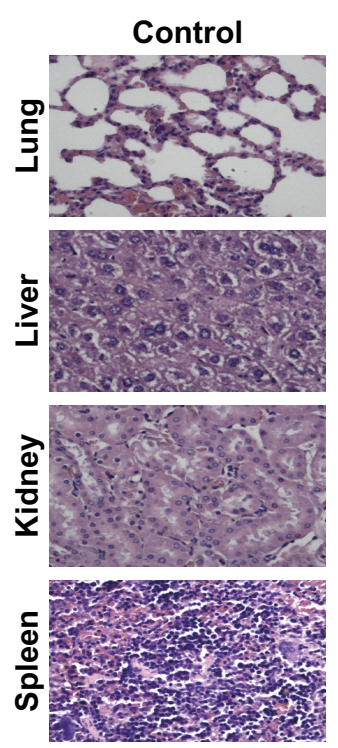
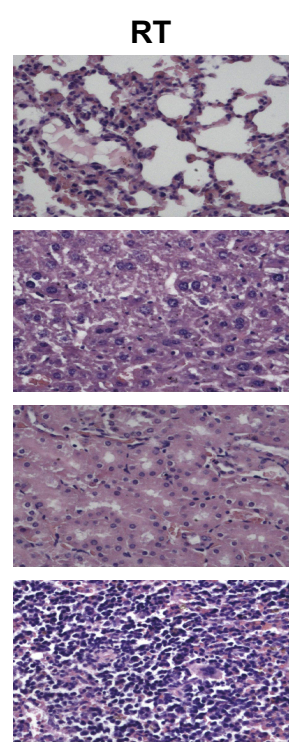

RT + S3I-201
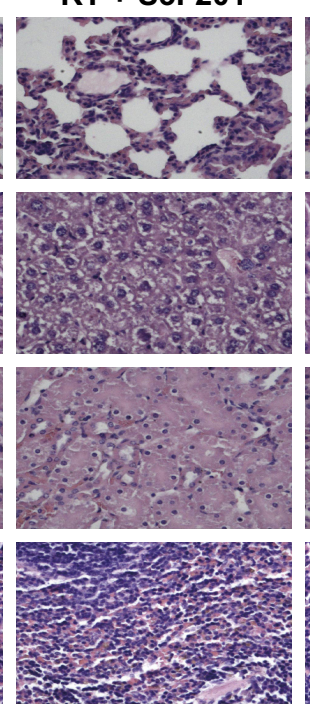

RT + apatinib $\quad R T$ + apatinib + S3I
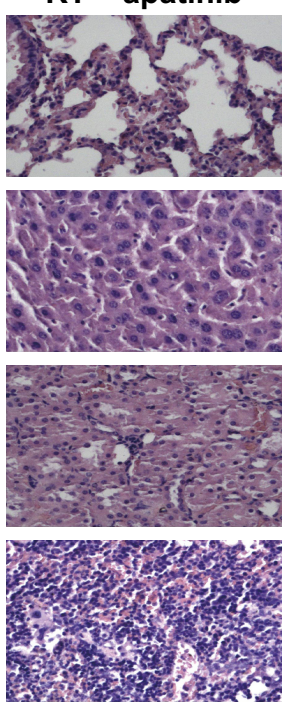
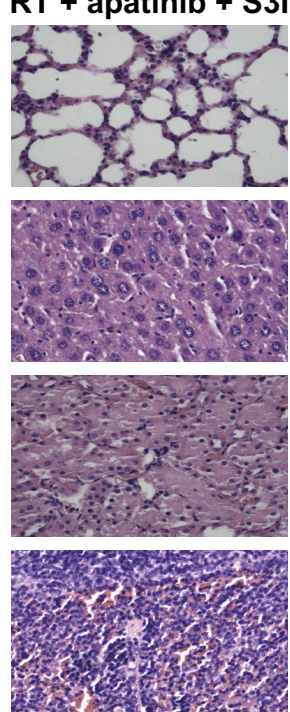

Figure 4 Toxicity analysis for treatments with apatinib and S3I-20I in mice bearing Calu-I cells.

Notes: (A) Tumor model and treatment schedule. About $5 \times 10^{6}$ Calu-I cells were subcutaneously injected into the mice. Ten days later, apatinib (200 mg/kg, once a day), S3I-20I (5 mg/kg, every 3 days), and radiotherapy were administered for I 4 days. Four groups of animals were exposed to I0 Gy radiation (radiation was applied at $6 \mathrm{MV}$ $\mathrm{X}$-ray and a dose rate of $2 \mathrm{~Gy} / \mathrm{min}$ with a source-skin distance of $100 \mathrm{~cm}, 2 \mathrm{~Gy}$ X/day, for five times). The mice were sacrificed on the next day after the last administration and the tumor weight was weighed to observe the antitumor effect. (B) Total body weight of mice was monitored for every 2 days. (C) H\&E histology of various organs after various treatments $(n=5)$.

Abbreviations: IR, irradiation; ig, intragastric administration; sc, subcutaneous; qd, every day; Con, control; RT, radiation treatment.

observations, we conclude that radiotherapy together with dual inhibition of VEGFR2 and STAT3 would be effective in producing an inhibitory effect on tumor growth in mice bearing Calu-1.

\section{Discussion}

Lung cancer is one of the leading diseases that pose a great threat to life and health. Radiotherapy is a key solution for treating small-cell lung cancer, especially in its late stage. However, the 5 -year survival rate is low (only $5 \%-10 \%$ ); about $80 \%$ of patients have local recurrence and $60 \%$ have distal metastasis. ${ }^{1}$ Treatment often becomes less effective because some tumor cells are resistant to radiation. While the combined use of anti-angiogenic drugs and radiotherapy can sensitize tumor cells to radiotherapy and improve a patient's condition in the short term, these agents have little long-term effects. An explanation for this observation is that when VEGFR2, an important factor for tumor growth, is inhibited, STAT3 in tumor cells may be activated as an alternative pathway to replace the function of VEGFR2, leading to resistance against radiotherapy. To address this issue, we conducted the current study to determine the effects of dual inhibition of both VEGFR2 and STAT3 on the sensitivity of tumor cells to radiotherapy as well as to elucidate the underlying mechanisms. Our results showed that when VEGFR2 in lung cancer cells was inhibited, STAT3 could lead to the regulation (directly or indirectly) of cyclin D1 expression, both of which worked together to improve the radiosensitivity of lung cancer cells. In vivo, we conclude that radiotherapy together with dual inhibition of VEGFR2 and STAT3 would 

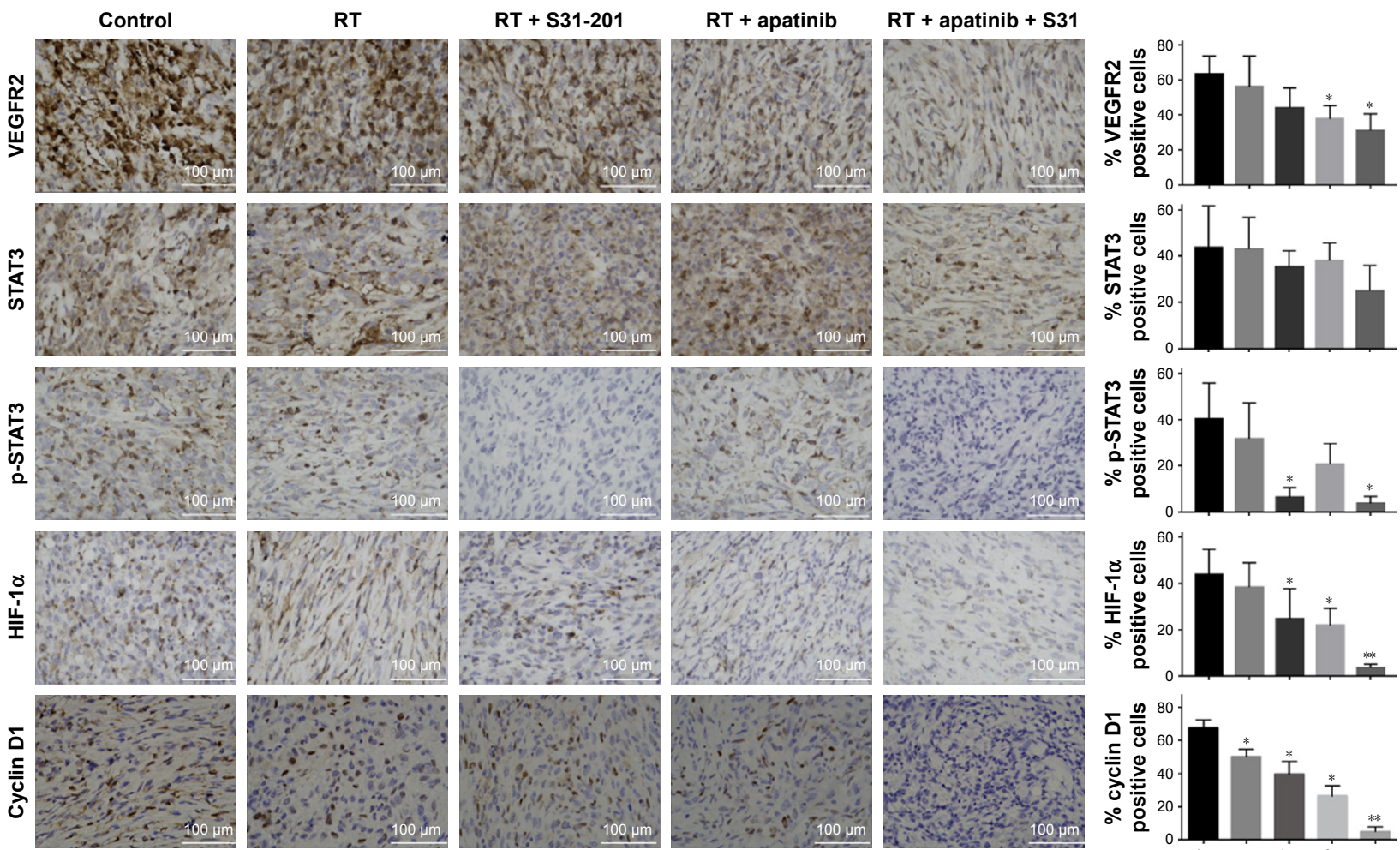

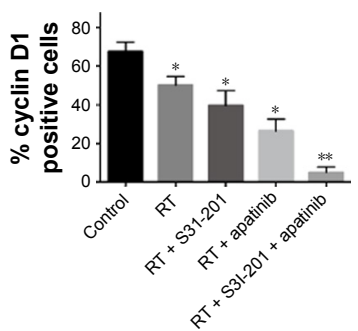

Figure 5 Effects of dual inhibition of VEGFR2 and STAT3 on the expression of downstream signaling molecules in tumor tissues.

Notes: Tumor tissues from xenograft animal model were analyzed by immunohistochemistry, and the effects of inhibition of VEGFR2/STAT3 alone or dual inhibition of VEGFR2 and STAT3 on the protein levels of VEGFR2, STAT3, P-STAT3, as well as their downstream signaling molecules HIF-I $\alpha$ and cyclin DI were determined. $* P<0.05$; $* *<<0.01$; $n=3$. Abbreviations: RT, radiation treatment; VEGFR2, vascular endothelial growth factor receptor 2 .

A

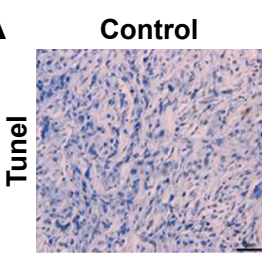

RT

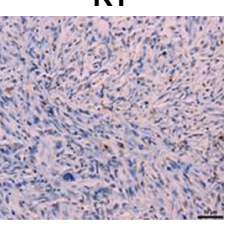

RT + S3I-201

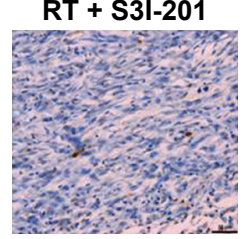

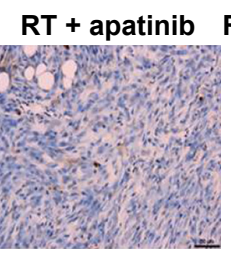

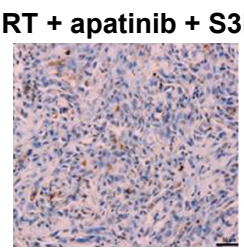

B

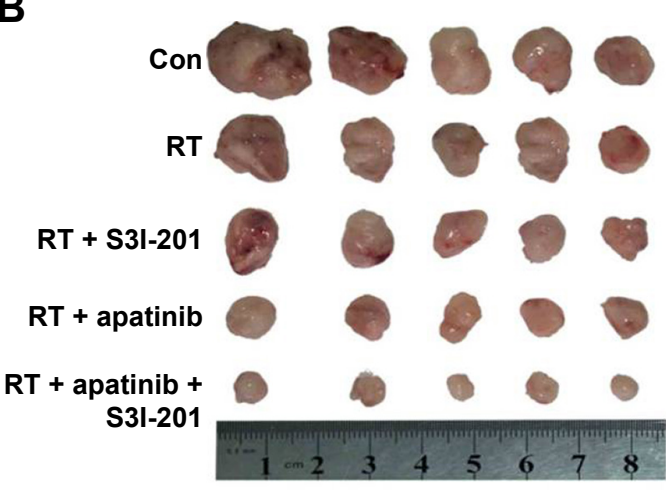

C

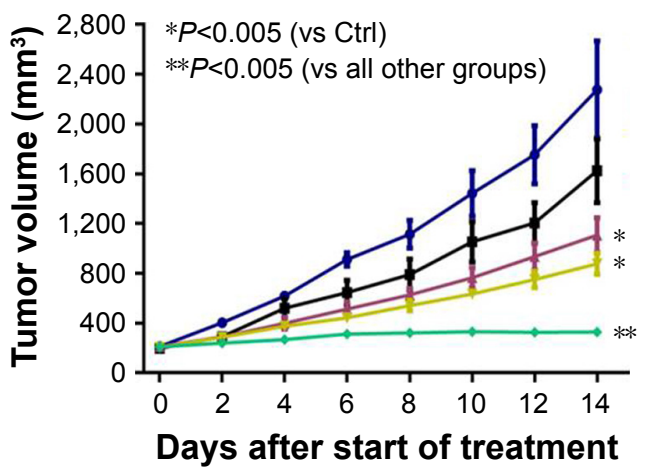

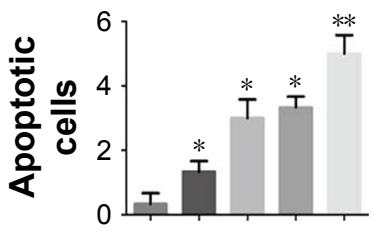

Figure 6 Combined treatment of radiotherapy together with dual inhibition of VEGFR2 and STAT3 in mice bearing Calu-I cells.

Notes: (A) Apoptosis of tumor tissues was evaluated by TUNEL staining. (B) Tumor growth delay of tumors in mice. (C) Tumor formation was evaluated every 2 days for 14 days. Tumor volume of xenograft mouse model was determined. $* P<0.05 ; * * P<0.0$ I; $n=5$.

Abbreviations: RT, radiation treatment; Con, control; VEGFR2, vascular endothelial growth factor receptor 2. 
be effective in producing an inhibitory effect on tumor growth in mice bearing Calu-1 cells. Therefore, the dual inhibition of VEGFR2 and STAT3 is effective in enhancing radiosensitivity in lung cancer therapy.

Our previous studies demonstrated that several strains of NSCLC cells express VEGFR2, and among them, Calu-1 cells have the highest levels of VEGFR2 expression and are also the most radioresistant. In addition, in these cells, inhibition of VEGFR2 improves radiosensitivity. ${ }^{7,8}$ Consistent with this, patients with high VEGFR2 expression in NSCLC tissues are resistant to radiotherapy, and their progression-free survival and OS are shorter than those in patients with low VEGFR2 expression. ${ }^{9}$ In a Phase II study where radiotherapy was combined with endostatin for NSCLC patients with brain metastasis, the investigators found no significant difference in the therapeutic efficacy between combined radiotherapy and radiotherapy alone. ${ }^{21}$ However, in a subgroup of patients with high VEGFR2 expression, the effects of the two therapies were significantly different, although no long-term benefit in survival was found. ${ }^{9}$ The possible reason may be that STAT3 is as alternative pathway that is activated in the tumor cells when VEGFR2 is inhibited, thereby replacing the role of VEGFR2 in resisting radiotherapy.

STAT3 is a nuclear transcription factor that can be activated by a number of factors such as cytokines and inflammatory mediators, and it is involved in the regulation of a variety of cell functions such as survival, proliferation, differentiation, and angiogenesis. ${ }^{22,23}$ Recent studies suggest that STAT3 plays a central role in the development of cancer radioresistance. ${ }^{13}$ STAT3 has been shown to enhance expression of regulatory factors and resistance to apoptosis-related genes. ${ }^{24}$ Therefore, anti-STAT3 and radiotherapy may be a potential therapeutic combination in the near future..$^{25,26}$ Phosphorylated STAT3 translocates to the nucleus where it regulates the downstream expression of target genes, such as HIF- $1 \alpha$ and cyclin D1, to influence the radiosensitivity of tumor cells. Similarly, HIF-1 $\alpha$ is another nuclear transcription factor that plays an important role in a tumor cell's radioresistence, and its expression can be regulated by STAT3. For example, Nechemia-Arbely et $\mathrm{al}^{17}$ reported that regardless of oxygen levels, STAT3 activation upregulated HIF-1 $\alpha$ expression in mouse kidney tumor cells, and there was a positive correlation between STAT3 activation and HIF-1 $\alpha$ expression. In agreement with this, our current study showed that the simultaneous inhibition of VEGFR2 and STAT3 resulted in the inhibition of HIF-1 $\alpha$ protein expression. Cyclin D1, a member of the cyclin family and encoded by the CCND1 gene, affects the efficacy of radiotherapy. Consistent with the findings of Won et al, ${ }^{27}$ we found that inhibition of STAT3 resulted in the decreased expression of cyclin D1 in Calu-1 cells. In accordance with these previous studies, we showed that lung tumor cells treated with both VEGFR2 and STAT3 inhibitors had reduced expression of HIF- $1 \alpha$ and cyclin D1 protein levels, which resulted in improved radiosensitivity. Together, these results indicate that STAT3 activation can affect the radiosensitivity of lung tumor cells by regulating cyclin D1 expression via direct and indirect pathways.

A study by Wen et $\mathrm{al}^{28}$ found that in both normal lung epithelial cells and tumor cells cultured under normoxia or hypoxia conditions, HIF- $1 \alpha$ can negatively regulate cyclin D1 expression through the working mechanism by which HIF-1 $\alpha$ directly interacts with hypoxia response element in the promoter region of cyclin D1 gene with involvement of histone deacetylase, ultimately leading to tumor cell radioresistance. In the current study, we found that the simultaneous inhibition of VEGFR2 and STAT3 was associated with decreased expression of their downstream signaling molecules HIF- $1 \alpha$ and cyclin D1, together with an increased radiosensitivity in lung cancer cells. These results are not in agreement with the results reported by Wen et al, ${ }^{28}$ who showed the negative regulation of cyclin D1 by HIF-1 $\alpha$. Activation of cyclin D1 transcription is regulated by several cis-acting elements such as AP-1, CRE, and Sp-1. ${ }^{29,30}$ Dogan et $\mathrm{al}^{31}$ showed that through the MAPK/ ERK pathway, KRAS regulates the downstream signaling molecule cyclin D1 expression to affect the proliferation and apoptosis of NSCLC cells. Our previous studies showed that VEGFR2 regulates HIF-1 $\alpha$ expression through MAPK/ERK pathways to affect tumor cell radiosensitivity. ${ }^{7}$ Together with the results from the current study, we conclude that the dual inhibition of VEGFR2 and STAT3 may inhibit MAPK/ERK pathways, leading to the reduced expression of both HIF-1 $\alpha$ and cyclin D1. In addition, inhibition of STAT3 alone is adequate to directly downregulate HIF-1 $\alpha$ and cyclin D1 expression. The mechanism by which HIF-1 $\alpha$ and cyclin D1 interact with each other remains to be investigated in the future studies. Cyclin D1 is an important member of the cell cycle regulation protein family, and is mainly produced in the early G1 phase and plays a key role in cell cycle progression from $\mathrm{G} 1$ to $\mathrm{S}$ phase. Cyclin D1 forms complex with cyclin-dependent kinase 4 (CDK4) and CDK6 and becomes activated. The cyclin D1/CDK4/6 complex can induce phosphorylation of the product of retinoblastoma $(\mathrm{Rb})$ gene (an anti-cancer gene) and the subsequent release of transcription factor E2F, which drives cell cycle progression from G1 to $\mathrm{S}$ phase, thus promoting cell division. ${ }^{32}$ Our previous 
work indicated that A549 cells showed low expression of VEGFR2., ${ }^{70}$ The low expression of VEGFR2 leads to poor efficacy of targeted VEGFR2 in A549 cells. ${ }^{7}$ However, the combined inhibition effect was significant in A549 cells with high STAT3 expression. The results in this study showed that dual inhibition of VEGFR2 and STAT3 resulted in increased cell death, increased number of cells in G2/M phase, and increased radiosensitivity in lung cancer cells. After the damage to DNA molecules by radiation, related genes could start the regulation of cell cycle and stop the cell cycle at G1/S or G2/M phase (two checkpoints). G2/M cell cycle arrest is the decisive factor affecting the radiosensitivity of tumor cells. Findings had shown that G2/M cell cycle arrest caused radiation resistance in malignant meningioma cells and breast cancer cells. ${ }^{33,34}$ Furthermore, pharmacological concentrations of ascorbate could radiosensitize glioblastoma multiforme primary cells by increasing oxidative DNA damage and inhibiting G2/M arrest. ${ }^{35}$ Unlike the observed increase in cell cycle progression from $\mathrm{G} 1$ to $\mathrm{S}$ phase driven by cyclin $\mathrm{D} 1$, He et $\mathrm{al}^{36}$ found that in breast cancer cells, upregulation of cyclin-dependent kinase 2 associate protein-1 (CDK2AP1) caused cell cycle arrest in G2/M phase and cell division was inhibited. At the same time, there was inverse correlation between CDK2/cyclin D1 and CDK2AP1 expressions. Though not tested, it is possible that CDK2AP1 might have also caused a G2/M arrest in the lung cancer cells in the current study. In view of the fact that apatinib and S3I-201 are not single-target drugs, future experiments should involve lentivirus-packaged siRNAs to knockdown VEGFR2/STAT3 and create an animal model of VEGFR2/ knockdown. This needs to be investigated in future studies.

In summary, in the current study using an in vitro and in vivo experimental model, we demonstrated that after inhibition of VEGFR2 expression in lung cancer cells, the inflammatory mediators and growth factors in the tumor microenvironment could also induce the activation of STAT3. STAT3 directly or indirectly regulates cyclin D1 expression, both of which work together to affect the radiosensitivity of lung cancer cells. Thus, the combined inhibition of VEGFR2 and STAT3 is effective in sensitizing to radiotherapy. These findings may be useful information for anti-cancer therapy in clinical practice.

\section{Acknowledgments}

This study was supported by the National Natural Science Foundation of China (No 81472792), the Youth Medical Talent Project of Jiangsu (QNRC2016499), the Health Family Planning Technology Project of Lianyungang (QN1602), and the Youth Talents Found of Lianyungang First People's Hospital (QN140201 and QN150101).

\section{Disclosure}

The authors report no conflicts of interest in this work.

\section{References}

1. Bayman N, Blackhall F, Mccloskey P, Taylor P, Faivre-Finn C. How can we optimise concurrent chemoradiotherapy for inoperable stage III non-small cell lung cancer? Lung Cancer. 2014;83(2):117-125.

2. Jiang X-Dong, Qiao Y, Dai P. Enhancement of recombinant human endostatin on the radiosensitivity of human pulmonary adenocarcinoma A549 cells and its mechanism. J Biomed Biotechnol. 2012;2012(10):1-8.

3. Jiang XD, Dai P, Wu J, Song DA, Yu JM. Inhibitory effect of radiotherapy combined with weekly recombinant human endostatin on the human pulmonary adenocarcinoma A549 xenografts in nude mice. Lung Cancer. 2011;72(2):165-171.

4. Jiang XD, Qiao Y, Dai P, et al. Preliminary clinical study of weekly recombinant human endostatin as a hypoxic tumour cell radiosensitiser combined with radiotherapy in the treatment of NSCLC. Clin Transl Oncol. 2012;14(6):465-470.

5. Jiang XD, Dai P, Wu J, Song DA, Yu JM. Effect of recombinant human endostatin on radiosensitivity in patients with non-small-cell lung cancer. Int J Radiat Oncol Biol Phys. 2012;83(4):1272-1277.

6. Jiang XD, Dai P, Qiao Y, Wu J, Song DA, Li SQ. Clinical study on the recombinant human endostatin regarding improving the blood perfusion and hypoxia of non-small-cell lung cancer. Clin Transl Oncol. 2012;14(6): 437-443.

7. Liu L, Qiao Y, Hu C, et al. Endostatin exerts radiosensitizing effect in non-small cell lung cancer cells by inhibiting VEGFR2 expression. Clin Transl Oncol. 2016;18(1):18-26.

8. Liu Y, Qiao Y, Hu C, et al. VEGFR2 inhibition by RNA interference affects cell proliferation, migration, invasion, and response to radiation in Calu-1 cells. Clin Transl Oncol. 2016;18(2):212-219.

9. Jiang X, Ding M, Qiao Y, Liu Y, Liu L. Recombinant human endostatin combined with radiotherapy in the treatment of brain metastases of non-small cell lung cancer. Clin Transl Oncol. 2014;16(7):630-636.

10. Ellis PM, Al-Saleh K. Multitargeted anti-angiogenic agents and NSCLC: clinical update and future directions. Crit Rev Oncol Hematol. 2012;84(1):47-58.

11. Gurbuz V, Konac E, Varol N, et al. Effects of AG490 and S3I-201 on regulation of the JAK/STAT3 signaling pathway in relation to angiogenesis in TRAIL-resistant prostate cancer cells in vitro. Oncol Lett. 2014;7(3):755-763.

12. Lin GS, Chen YP, Lin ZX, Wang XF, Zheng ZQ, Chen L. STAT3 serine 727 phosphorylation influences clinical outcome in glioblastoma. Int J Clin Exp Pathol. 2014;7(6):3141-3149.

13. Spitzner M, Roesler B, Bielfeld C, et al. STAT3 inhibition sensitizes colorectal cancer to chemoradiotherapy in vitro and in vivo. Int J Cancer. 2014;134(4):997-1007.

14. Lu S, Gao Y, Huang X, Wang X. GYY4137, a hydrogen sulfide $\left(\mathrm{H}_{2} \mathrm{~S}\right)$ donor, shows potent anti-hepatocellular carcinoma activity through blocking the STAT3 pathway. Int J Oncol. 2014;44(4):1259-1267.

15. Islam M, Sharma $\mathrm{S}$, Teknos TN. RhoC regulates cancer stem cells in head and neck squamous cell carcinoma by overexpressing IL-6 and phosphorylation of STAT3. PLoS One. 2014;9(2):e88527.

16. Siveen KS, Sikka S, Surana R, et al. Targeting the STAT3 signaling pathway in cancer: role of synthetic and natural inhibitors. Biochim Biophys Acta. 2014;1845(2):136-154.

17. Nechemia-Arbely $Y$, Khamaisi M, Rosenberger C, et al. In vivo evidence suggesting reciprocal renal hypoxia-inducible factor-1 upregulation and signal transducer and activator of transcription 3 activation in response to hypoxic and non-hypoxic stimuli. Clin Exp Pharmacol Physiol. 2013; 40(4):262-272. 
18. Zhang XM, Zhou C, Gu H, Yan L, Zhang GY. Correlation of RKIP, STAT3 and cyclin D1 expression in pathogenesis of gastric cancer. Int J Clin Exp Pathol. 2014;7(9):5902-5908.

19. Shimura T. Targeting the AKT/cyclin D1 pathway to overcome intrinsic and acquired radioresistance of tumors for effective radiotherapy. Int $J$ Radiat Biol. 2017;93(4):381-385.

20. Hu C, Zhu P, Xia Y, Hui K, Wang M, Jiang X. Role of the NRP1-mediated VEGFR2-independent pathway on radiation sensitivity of non-small cell lung cancer cells. J Cancer Res Clin Oncol. 2018;144(7): 1329-1337.

21. Jiang XD, Ding MH, Qiao Y, Liu Y, Liu L. Study on lung cancer cells expressing VEGFR2 and the impact on the effect of RHES combined with radiotherapy in the treatment of brain metastases. Clin Lung Cancer. 2014;15(2):e23-e29.

22. Wang L, Yi T, Zhang W, Pardoll DM, Yu H. IL-17 enhances tumor development in carcinogen-induced skin cancer. Cancer Res. 2010;70(24): 10112-10120.

23. Yan B, Wei JJ, Yuan Y, et al. IL-6 cooperates with G-CSF to induce protumor function of neutrophils in bone marrow by enhancing STAT3 activation. J Immunol. 2013;190(11):5882-5893.

24. Zang C, Liu X, Li B, et al. IL-6/STAT3/TWIST inhibition reverses ionizing radiation-induced EMT and radioresistance in esophageal squamous carcinoma. Oncotarget. 2017;8(7):11228-11238.

25. Deng J, Liang H, Zhang R, et al. STAT3 is associated with lymph node metastasis in gastric cancer. Tumour Biol. 2013;34(5):2791-2800.

26. Bu X, Zhao C, Wang W, Zhang N. GRIM-19 inhibits the STAT3 signaling pathway and sensitizes gastric cancer cells to radiation. Gene. 2013;512(2):198-205.

27. Won C, Lee CS, Lee JK, et al. CADPE suppresses cyclin D1 expression in hepatocellular carcinoma by blocking IL-6-induced STAT3 activation. Anticancer Res. 2010;30(2):481-488.
28. Wen W, Ding J, Sun W, et al. Suppression of cyclin D1 by hypoxiainducible factor-1 via direct mechanism inhibits the proliferation and 5-fluorouracil-induced apoptosis of A549 cells. Cancer Res. 2010; 70(5):2010-2019.

29. Kim YM, Geiger TR, Egan DI, Sharma N, Nyborg JK. The HTLV-1 tax protein cooperates with phosphorylated CREB, TORC2 and p300 to activate CRE-dependent cyclin D1 transcription. Oncogene. 2010;29(14):2142-2152.

30. Zhang HS, Yan B, Li XB, et al. PAX2 protein induces expression of cyclin D1 through activating AP-1 protein and promotes proliferation of colon cancer cells. J Biol Chem. 2012;287(53):44164-44172.

31. Dogan Turacli I, Ozkan AC, Ekmekci A. The comparison between dual inhibition of mTOR with MAPK and PI3K signaling pathways in KRAS mutant NSCLC cell lines. Tumour Biol. 2015;36(12):9339-9345.

32. Sun Y, Luo D, Liao DJ. CyclinD1 protein plays different roles in modulating chemoresponses in MCF7 and MDA-MB231 cells. J Carcinog. 2012;11(1):12.

33. Gogineni VR, Nalla AK, Gupta R, Dinh DH, Klopfenstein JD, Rao JS. Chk2-mediated G2/M cell cycle arrest maintains radiation resistance in malignant meningioma cells. Cancer Lett. 2011;313(1):64-75.

34. Anastasov N, Höfig I, Vasconcellos IG, et al. Radiation resistance due to high expression of miR-21 and G2/M checkpoint arrest in breast cancer cells. Radiat Oncol. 2012;7(1):206.

35. Herst PM, Broadley KW, Harper JL, Mcconnell MJ. Pharmacological concentrations of ascorbate radiosensitize glioblastoma multiforme primary cells by increasing oxidative DNA damage and inhibiting G2/M arrest. Free Radic Biol Med. 2012;52(8):1486-1493.

36. He X, Xiang H, Zong X, et al. CDK2-AP1 inhibits growth of breast cancer cells by regulating cell cycle and increasing docetaxel sensitivity in vivo and in vitro. Cancer Cell Int. 2014;14(1):130.
OncoTargets and Therapy

\section{Publish your work in this journal}

OncoTargets and Therapy is an international, peer-reviewed, open access journal focusing on the pathological basis of all cancers, potential targets for therapy and treatment protocols employed to improve the management of cancer patients. The journal also focuses on the impact of management programs and new therapeutic agents and protocols on

\section{Dovepress}

patient perspectives such as quality of life, adherence and satisfaction The manuscript management system is completely online and includes a very quick and fair peer-review system, which is all easy to use. Visit http://www.dovepress.com/testimonials.php to read real quotes from published authors. 